\title{
TELEMETRIA PARA A FROTA DO TRANSPORTE URBANO DE PASSAGEIROS
}

\author{
Fernando Cesar Bastos Filho ${ }^{1}$ e Marcelo Massarani ${ }^{2}$ \\ ${ }^{1}$ Escola Politécnica da Universidade de São Paulo \\ ${ }^{2}$ Viação Santa Brígida Ltda.
}

E-mails: fernandocesar@ santabrigida.com.br, massarani@me.com

\begin{abstract}
RESUMO
Este artigo visa apresentar os efeitos da aplicação da Telemetria para a gestão de frotas do transporte de passageiros. Através da informação tecnológica extraída do ônibus com a aplicação da solução de Telemática em seu barramento CAN (Controller Area Network ou Ârea de Controle da Rede, em português), é possível obter com precisão indicadores que norteiam melhores práticas de gestão e aumentam o desempenho operacional, técnico e de recursos humanos no âmbito corporativo e público. O processo evolutivo deste artigo indica redução e prevenção de acidentes e sinistros operacionais, redução do consumo de combustível e do impacto ambiental e aumento da quilometragem média entre falhas técnicas do ônibus. Contudo, projetam-se os efeitos do aumento de eficiência na administração pública e privada do transporte de passageiros, carente do uso de recursos tecnológicos mais eficientes para gestão de suas frotas pelo Brasil.
\end{abstract}

\section{INTRODUÇÃO}

Segundo Schwab [1], estamos testemunhando mudanças profundas em todos os setores, possibilitando visualizar o surgimento de novos modelos de negócio, automação de processos e nova concepção do processo produtivo, do consumo, dos transportes e dos sistemas logísticos. Ainda de acordo com Schwab [1], de certa forma, existe a insegurança que cerca a projeção e aplicação de tecnologias emergentes, concluindo que ainda desconhecemos as etapas das transformações geradas pela atual revolução industrial (denominada "Quarta Revolução Industrial”). Todavia, a rede complexa entre os setores requer que todo o público estratégico da sociedade global - governos, empresas, universidades e sociedade civil trabalhem juntos para compreender estas tendências ascendentes em rumo de desenvolvimento.

A Telemática aplicada em frotas contempla os sistemas de transmissão de informações do veículo e para o veículo, via de regra, analisadas automaticamente. O conceito "Telemática" deriva-se da unificação das palavras "telecomunicação" e "informática" [2].

Para a gestão de frotas, usualmente, utiliza-se como principal meio de transmissão para a telecomunicação a telefonia celular com o auxílio da tecnologia GSM (Global System for Mobile Communication ou Sistema Global de Comunicação Móvel, em português), possibilitando a troca de informações de forma bidirecional entre o ônibus e a central que o monitora. Neste caso, é possível conectar uma quantidade sem restrições de unidades à cadeia 
monitorada [2]. Este formato de gestão remota dos veículos é denominado de FMS (Fleet Management System ou Sistema de Gerenciamento de Frota, em português). Esta rede de conexão para gestão de frota é representada na Figura 1.

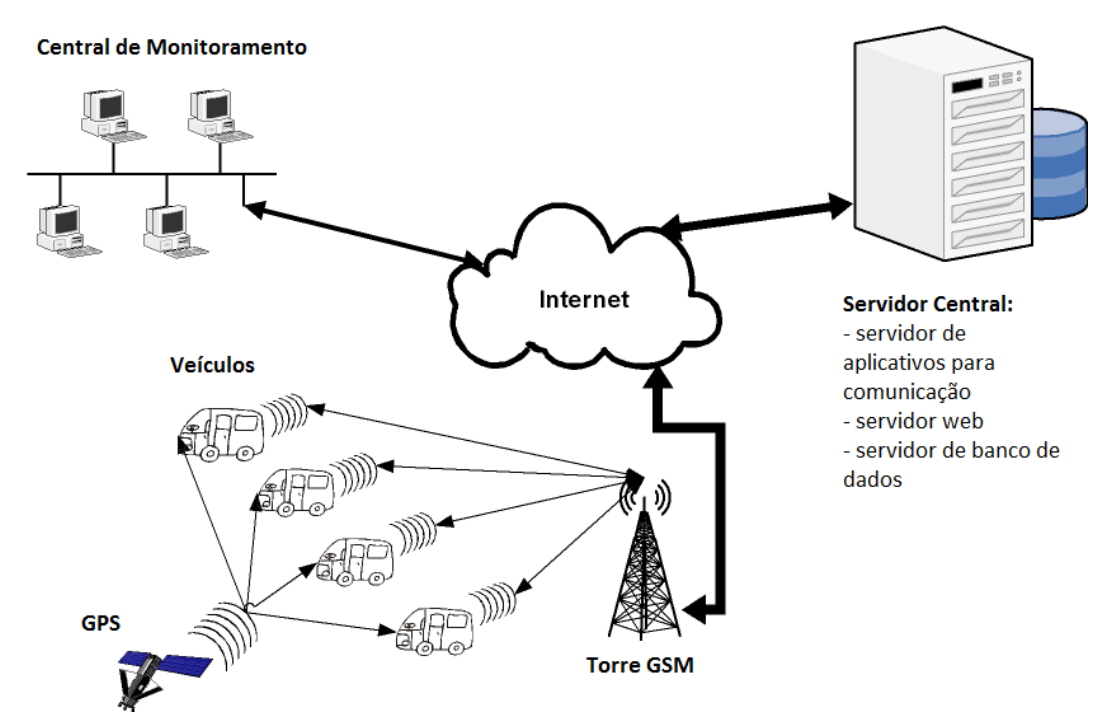

Figura 1. Estrutura FMS (adaptado [3]).

Entende-se como Telemetria a transmissão em tempo real dos parâmetros operacionais existentes, ou seja, por medição remota. Desta forma, além do modo de condução, é possível também monitorar pressões, temperaturas e atuações críticas no qual o veículo está sendo submetido [2]. A central de monitoramento poderá contatar o condutor, possibilitando reação rápida as anormalidades, corretivamente ou preventivamente. Entre os componentes da rede FMS, responsabilizam-se pela interface os aparelhos que dispõem de um módulo GSM e de um receptor GPS (Global Positioning System, ou Sistema de Posicionamento Global, em português), permitindo a localização do veículo e uso de todos os serviços associados a Telemática. O modelo de módulo de interface está apresentado na Figura 2.

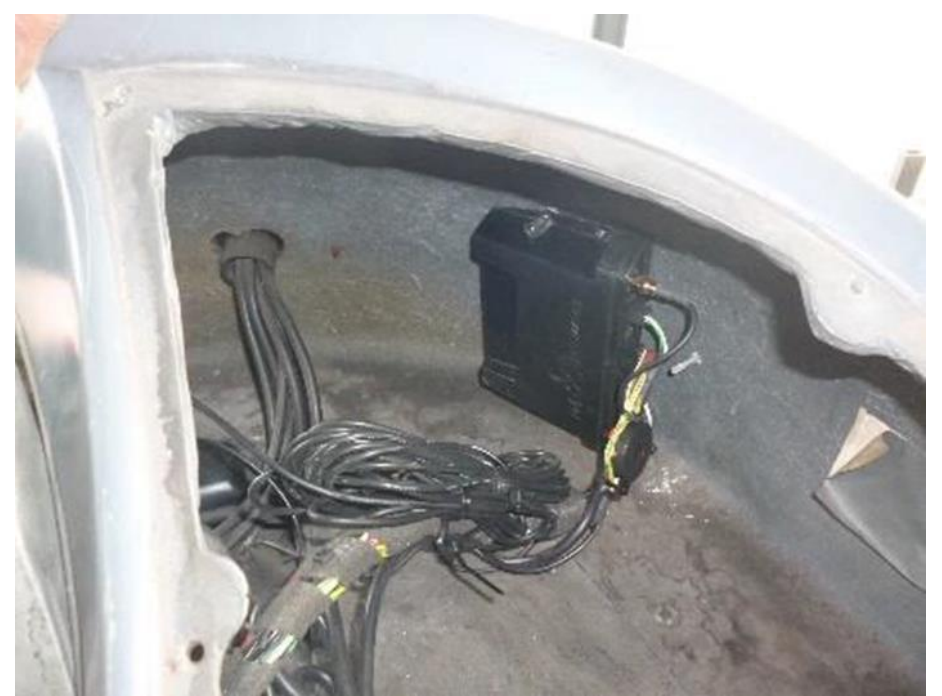

Figura 2. Módulo de interface Telemática instalado em veículo. 
A tecnologia FMS pode oferecer dois tipos de aplicações básicas de serviços [2]:

Gerenciamento de frota que apoia o veículo em sua aplicação operacional, trazendo benefícios a empresa de transporte ou organização pública que tem como objetivo disponibilizar sua frota do modo mais eficiente possível;

Colocar o próprio veículo como meio operacional em evidência. Isso possibilita que o fabricante do veículo realize diagnósticos de todos os seus componentes monitorados por ECU's (Eletronic Control Unit ou Unidade de Controle Eletrônico, em português) durante todo o período de utilização, acompanhando seu desempenho, com monitoramento de possíveis falhas, dando condição ao desenvolvimento de melhorias contínuas de seu produto.

O ITS (Intelligent Transport System ou Sistema Inteligente de Transporte, em português) evoluiu ao longo de quase 50 anos, iniciando sua aplicação em países europeus e asiáticos [4] - pioneiros neste desenvolvimento tecnológico. Entretanto, nota-se a necessidade de expansão das soluções do ITS nas metrópoles da América do Sul, sobretudo no sistema de transporte da cidade de São Paulo, que contém a maior frota de ônibus do mundo com aproximadamente 14.500 veículos [5].

Embora exista a diversidade de aplicação de equipamentos de tecnologia embarcada para uma melhor composição do ITS, o atual cenário da frota urbana da região metropolitana e capital do estado de São Paulo usufrui parcialmente destas soluções - as quais já são bem exploradas na Europa, Ásia e América do Norte [4].

Da forma explorada por Guimarães [6], desenvolveu-se pela empresa alemã Robert Bosch por volta de 1980 o CAN Bus (barramento Controller Area Network ou Área de Controle da Rede, em português), desenvolvido inicialmente para ônibus e caminhões. Nos dias de hoje, é aplicado amplamente no regime industrial, na automobilística como um todo, no segmento naval, agrícola, entre outros.

Ainda segundo Guimarães [6], conceitualmente, o CAN se trata de um protocolo de comunicação serial síncrono, ou seja, existe o sincronismo entre a conexão de módulos eletrônicos à rede que se relaciona ao princípio de cada mensagem informada ao barramento. Essa transmissão é feita a partir de fios elétricos e, dependendo de sua aplicação, pode conectar centenas de módulos. Enfatizando sua aplicação no segmento automotivo, trata-se do protocolo de maior amplitude e quantidade de aplicações.

Os métodos tradicionais de gestão de performance operacional de frotas são baseados em análises subjetivas e deslocamentos físicos de colaboradores analistas ao viário, responsáveis por monitorar as técnicas de condução do motorista e as condições de pavimentação na qual o veículo é aplicado. Geralmente, as análises são motivadas por efeitos de falhas, ou seja, como ação corretiva.

Diante deste cenário e sob a necessidade de aumentar sua eficiência operacional, o Grupo NSO (Nossa Senhora do Ó) desenvolveu o Projeto Intelemétrica, que consiste na criação de um modelo de gestão apoiado na Telemetria, possibilitando extração de informações operacionais do veículo e comunicando-as com a gestão de Operações e de Manutenção, tornando mais assertiva a tomada de decisão em relação aos processos de performance 
operacional e confiabilidade técnica da frota, do mesmo modo, trazendo benefícios diretos a segurança e redução de custos.

O início da aplicação da Telemetria na gestão das frotas do Grupo NSO nasceu da parceria com a Volvo Bus, onde em determinada aquisição de frota foram instalados em 100 ônibus da Viação Santa Brígida - uma das empresas do Grupo NSO - os módulos de Telemetria da plataforma Volvo Bus Telemática, focada em gerenciamento de frotas. Trata-se do primeiro contato do Grupo NSO com os dados obtidos por Telemetria, que dentro de experiência inicial positiva, possibilitou no $1^{\circ}$ semestre das avaliações: redução de $37 \%$ no total de colisões; aumento de 19\% na quilometragem média entre falhas - MKBF (Mean Kilometer Between Failure ou Quilometragem Média entre Falhas, em português); redução de 5,37\% no consumo de combustível [7].

Assim sendo, o objetivo deste estudo é apresentar as possibilidades de operação do serviço de transporte de passageiros com excelência, atendendo as expectativas dos contratantes - seja público ou privado. Da mesma forma, indicar o momento de manutenção eficaz dos veículos, mantendo a confiabilidade e custos sob controle.

\section{OBJETIVO}

Recomenda-se a aplicação do modelo de gestão adotado no desenvolvimento do Projeto Intelemétrica, com o objetivo de trazer soluções para a decisão pública e privada na gestão técnico-operacional das frotas, otimizando a operação do transporte de passageiros, aumentando a confiabilidade e segurança dos ônibus, culminando em redução de custos operacionais.

\section{METODOLOGIA}

\subsection{Benchmarking}

Dentro da necessidade de aprimorar o conceito de gestão com uso da Telemetria, alguns benchmarkings (ou avaliações comparativas, em português) internacionais foram realizados ao longo do projeto, visando conhecer novas experiências e incorporar as melhores práticas adaptadas a realidade do Grupo NSO, com o objetivo principal de aperfeiçoar os métodos de gestão. A seguir, serão descritos os principais pontos técnicos e gerenciais observados nas visitas realizadas.

Volvo Bus

País / Cidade: Suécia / Gotemburgo

Período: Julho/2015

Objetivos: Conhecer processo de gestão e operação com apoio da Telemetria; conhecer novas tecnologias para aplicação em frota

Inicialmente, foi realizada análise da operação de Gotemburgo inloco (no viário), conhecendo a logística técnico-operacional BRT (Bus Rapid Transit ou Trânsito de Ônibus Rápido, em português) da frota monitorada com Telemetria, aplicada em veículos Volvo Euro 5, Euro 6, Híbridos, Elétrico-Híbridos e Elétricos. Foi observada também a aplicação de interface eletrônica para uso do motorista, a fim de obter as informações em tempo real transmitidas pela Telemetria. 
$\mathrm{Na}$ sequencia, houve visita a matriz Volvo com workshop (oficina, em português) especializado em Telemetria - Gestão de Tráfego e Frota, a fim de conhecer o processo construtivo e de planejamento da Central de Monitoramento e Controle por Telemetria. Da mesma forma, entender o acompanhamento operacional no veículo Elétrico-Híbrido via Central de Monitoramento, bem como a performance de seu Power Train (trem-de força, em português).

Este benchmarking foi fundamental para o desenvolvimento do Setor de Inteligência Telemétrica do Grupo NSO, onde foi possível entender quais são os recursos tecnológicos necessários, formato de monitoramento e quadro de pessoal ideal para as atividades de análise.

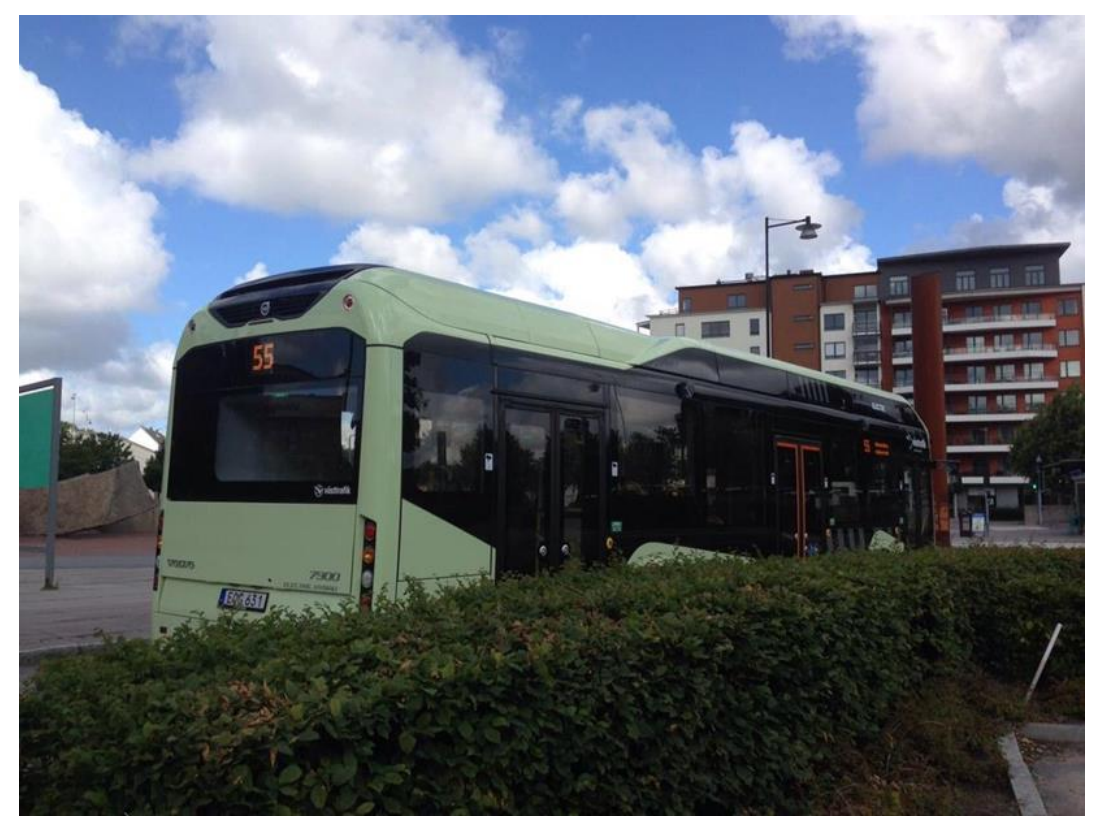

Figura 3. Linha assistida por Telemetria (ônibus Elétrico-Híbrido).

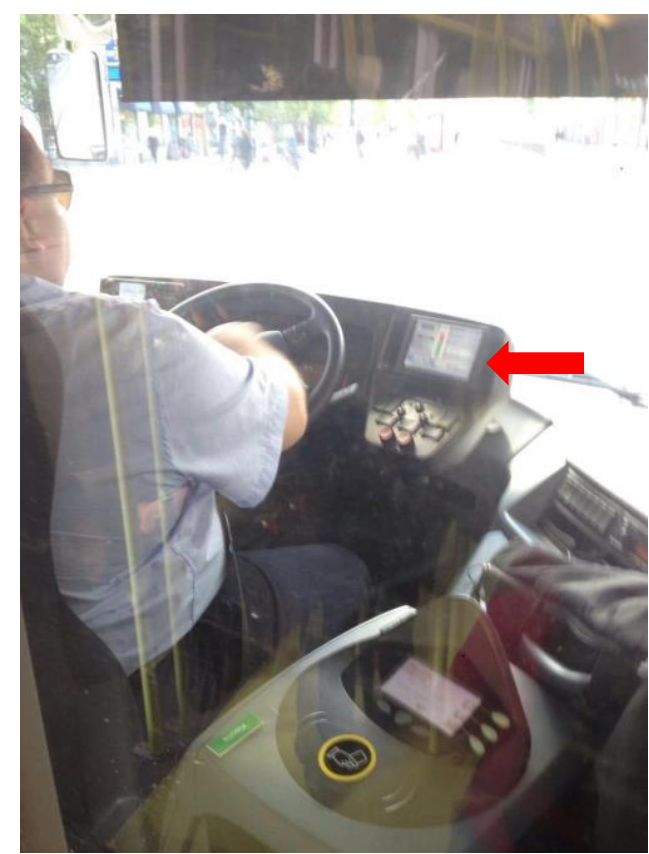

Figura 4. Interface do motorista via Telemática. 


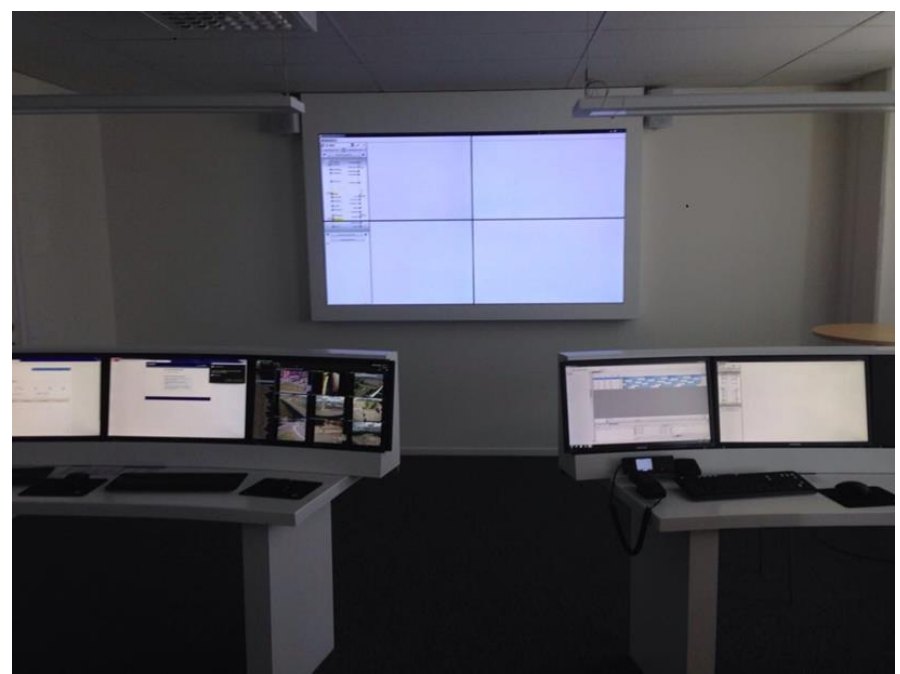

Figura 5. Central de Monitoramento e Controle por Telemetria.

\section{WMATA}

País / Cidade: Estados Unidos / Washington DC;

Período: Outubro/2015

Objetivos: Acompanhamento da operação de transporte público com ITS; conhecer ferramentas de gestão de garagem, voltado exclusivamente à organização e disponibilização de frota.

A WMATA é a Autoridade de Trânsito da Área Metropolitana de Washington DC, dividindo-se em 3 tipos de serviços: Metrorail, Metroaccess, e Metrobus - alvo do benchmarking. A frota da Metrobus detém cerca de 1.500 ônibus em sua composição, atendendo mais de 300 linhas.

Monitorando a performance operacional da WMATA / Metrobus, aplicam-se as soluções de Telemática que ajudam a resolver os principais desafios da gestão do transporte público, da mesma forma, favorecendo a mobilidade dos cidadãos e aumentando a atratividade do transporte público.

O benchmarking possibilitou conhecer a aplicação da tecnologia para monitoramento automático dos veículos, despacho de veículos auxiliados por Telemetria, meios de controle para uso sustentável e eficiente de combustível, equipamentos de infotainment para interface com a operação e gestão eletrônica da garagem.

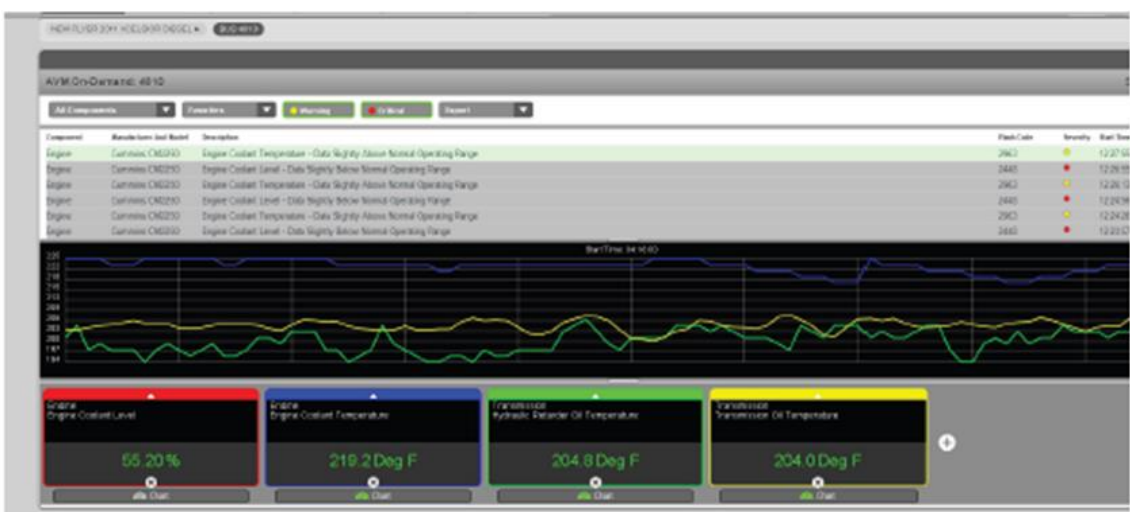

Figura 6. Monitoramento do arrefecimento da frota por Telemetria. 


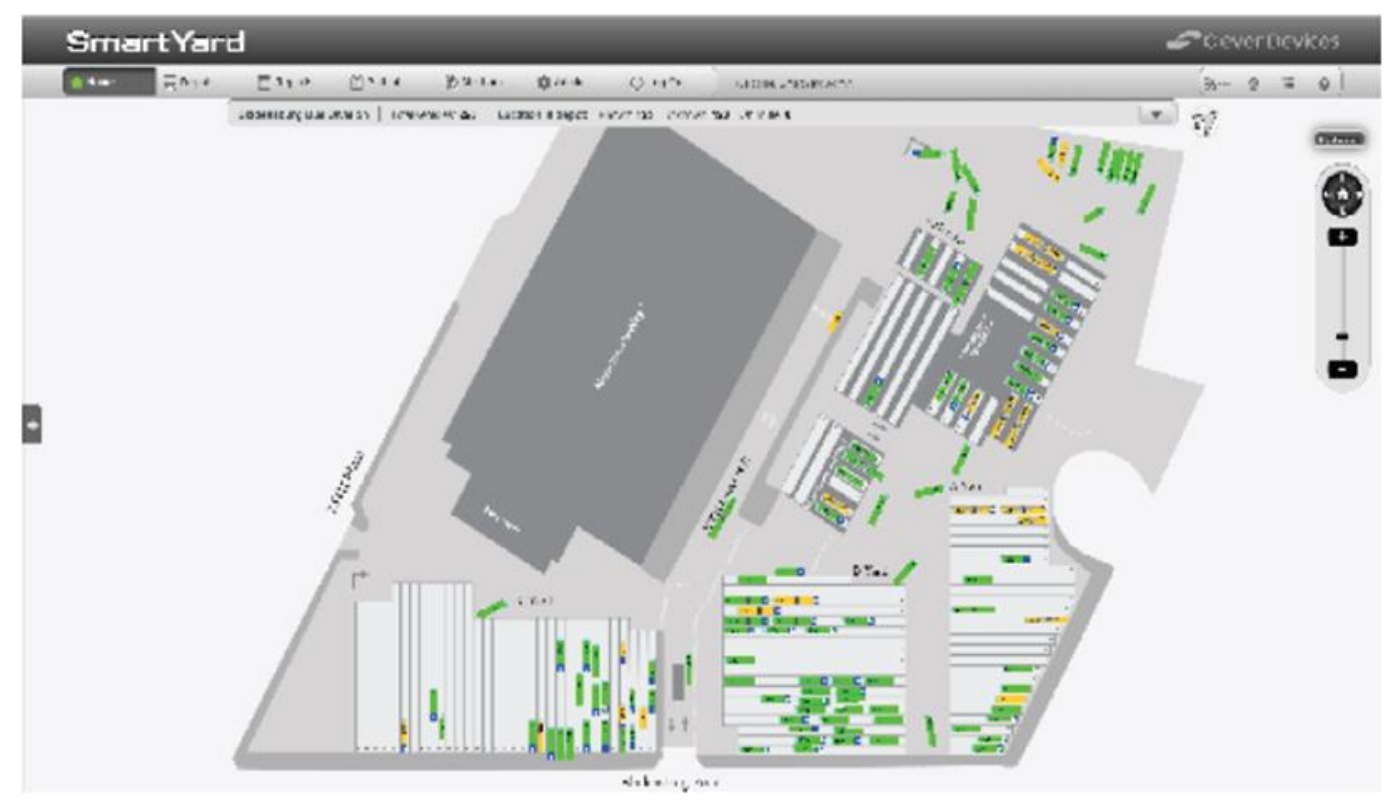

Figura 7. Monitoramento eletrônico do despacho da frota.

Go-Ahead London

País / Cidade: Inglaterra / Londres;

Período: Junho/16

Objetivos: Conhecer práticas de gestão operacional e técnica com uso da Telemetria.

A Go-Ahead London possui cerca de 2000 veículos na frota, distribuindo seus ônibus em 17 garagens, compostas pelas marcas Volvo, Scania, Mercedes-Benz, ADL e iniciando testes com ônibus elétricos da BYD. A distribuição da frota nas garagens é feita de acordo com a tecnologia de carroceria - single ou double deck (plataforma simples ou dupla, em português) - e a infraestrutura que pode receber os respectivos veículos.

A frota utiliza da Telemetria em sua gestão há 7 anos, onde os dados obtidos são armazenados em ambiente Cloud (nuvem), ou seja, não possuem servidor e/ou banco de dados específico na empresa para armazenamento dos dados.

A gestão das informações é voltada exclusivamente a performance do motorista. Toda semana, os Gerentes e Supervisores das garagens encaminham as análises de performance ao Gerente Geral da Go-Ahead London, sob uma análise macro chamada RAG - Red, Ambar e Green (Vermelho, Ambar e Verde, em português). Trata-se de uma análise de ranking de motoristas escaladas entre cores, sendo: Verde $=$ Alto Desempenho; Vermelho $=$ Baixo Desempenho. Este relatório é desenvolvido respeitando os limites gabaritados de cada operação / linha.

O indicador do motorista é composto por vários outros indicadores (frenagens, aceleração, curvas, etc.) e o Gerente Geral obtém o status da performance operacional de cada garagem. Todos os ônibus são equipados com interface que transmite o feedback (comentário, em português) sobre a performance de direção ao motorista em tempo real. Todavia, o grande ponto é que todo motorista tem em seu celular pessoal um aplicativo específico, que mostra seu resultado individual diário e acumulativo em gráficos de simples visualização. 
As orientações dos motoristas são feitas mensalmente e passam primeiramente pela etapa do diálogo entre Operador e Supervisor. $\mathrm{Na} 1^{\text {a }}$ reincidência de falhas, os indicados passam por treinamento do item destacado na Telemetria. Havendo a $2^{\mathrm{a}}$ reincidência, o Motorista é orientado pelo Gerente de Operações da Garagem. A $3^{\text {a }}$ reincidência caminha para medidas disciplinares (o que é raro).

A partir do $4^{\circ}$ ano de uso, a Go-Ahead London entrou com programa de premiação pela alta performance medida via Telemetria. Os relatórios de performance (RAG) são fechados semanalmente e os destaques positivos recebem $£ 20$ por semana.

Semanalmente, o prestador de serviços de Telemática verifica as condições de conexão que asseguram a transmissão sem interrupções. Os melhores do ano são selecionados para uma competição interna de alta performance, com limites mais rígidos nos indicadores, onde o vencedor ganha um carro popular como prêmio. Fora os benefícios operacionais, o equipamento possibilitou redução de consumo de combustível em $20 \%$ entre o $1^{\circ}$ e $2^{\circ}$ ano de operação.

Este, sem dúvida, foi um importante benchmarking para moldar a estrutura gerencial do Projeto Intelemétrica no Grupo NSO.

\subsection{Piloto}

O Grupo NSO deu início a aplicações-teste com unidades de Telemetria distribuídas pelas frotas das empresas Viação Santa Brígida (VSB), Auto Viação Urubupungá (AVU), Urubupungá Transportes e Turismo (UTT) e Viação Cidade de Caieiras (VCC). Estes testes possibilitaram o início da expansão de aplicações nas frotas, estruturando o gerenciamento das informações entre áreas e sequenciando a implementação nas frotas baseado em cronograma de instalações e treinamentos.

Os módulos de Telemetria foram instalados em veículos aleatórios, sem conhecimento dos motoristas, sendo:

VSB: 1 Volvo B290R

AVU: 1 Mercedes-Benz OF 1721

UTT: 1 Mercedes-Benz O500M

VCC: 1 Volkswagen 17-230 EOD

Os motoristas deram sequencia com a rotina de atividades, sendo monitorados por 45 dias;

Após o "teste-cego", os relatórios e resultados de monitoramento foram apresentados aos motoristas;

Os motoristas seguiram com as atividades operacionais sob ciência do monitoramento por mais 45 dias de acompanhamento;

Terminado o período, os motoristas foram convocados para nova apresentação das informações monitoradas e análise de evolução.

Observou-se evolução positiva entre o período de teste considerando apenas o 'efeito psicológico'. Ou seja, o motorista não foi treinado, apenas ciente que estava sendo monitorado. Na Tabela 1, demonstram-se os resultados de evolução do teste, focando nos eventos associados ao consumo de combustível: 


\begin{tabular}{|c|c|c|c|c|c|c|}
\hline \multirow{2}{*}{ Empresa NSO } & \multirow{2}{*}{$\begin{array}{c}\text { Fase do } \\
\text { teste }\end{array}$} & \multicolumn{3}{|c|}{ Eventos de Condução } & \multirow{2}{*}{$\begin{array}{l}\text { Consumo } \\
\text { (Km / litro) }\end{array}$} & \multirow{2}{*}{ \% Evolução } \\
\hline & & ER / Dia & FFV / Dia & MLE / Dia & & \\
\hline \multirow{2}{*}{ VSB } & 1 & 258 & 503 & 7 & 1,64 & \multirow{2}{*}{$6,7 \%$} \\
\hline & 2 & 22 & 147 & 3 & 1,75 & \\
\hline \multirow{2}{*}{ AVU } & 1 & 597 & 2.807 & 5 & 2,13 & \multirow{2}{*}{$6,1 \%$} \\
\hline & 2 & 52 & 1906 & 2 & 2,26 & \\
\hline \multirow{2}{*}{ UTT } & 1 & 9 & 447 & 4 & 3,95 & \multirow{2}{*}{$11,4 \%$} \\
\hline & 2 & 8 & 286 & 2 & 4,40 & \\
\hline \multirow{2}{*}{ VCC } & 1 & 488 & 830 & 3 & 1,87 & \multirow{2}{*}{$9,6 \%$} \\
\hline & 2 & 38 & 721 & 2 & 2,05 & \\
\hline
\end{tabular}

Legenda:

ER Excesso de rotação

FFV Condução fora da faixa verde

MLE Marcha-lenta excessiva

Tabela 1. Evolução da aplicação dos testes.

Considerações críticas:

Os testes foram aplicados em um veículo de cada empresa, a fim de avaliar o comportamento da leitura do barramento CAN em diferentes modelos e potências;

Foram avaliados 2 motoristas por veículo $-1^{\circ}$ e $2^{\circ}$ turno;

VSB, AVU e VCC operam em regime urbano; UTT opera em regime rodoviário;

O chassi testado na VSB contém transmissão automática, favorecendo maior controle sobre o excesso de rotação e condução fora da faixa verde; nos chassis das demais empresas, aplicam-se transmissão mecânica;

Entende-se como fase 1 e 2 do teste o momento antes e depois do "teste-cego".

Parâmetros para apontamento dos eventos:

Excesso de rotação superior a 3.000 RPM em operação;

Operação abaixo ou acima da faixa verde maior que 5 segundos;

Veículo submetido a marcha lenta por tempo que excede 5 minutos.

Recomendações transmitidas pós-teste:

Manter os motoristas com veículo fixo;

Realizar campanhas mensais para redução dos eventos de condução;

Emissão de relatórios periódicos;

Orientação via comunicação e mídia interna;

Realizar ações de treinamento apoiadas pela área de Recursos Humanos;

Construir ranking com a performance operacional dos motoristas.

\subsection{Estruturação Gerencial}

Após aprovação dos testes, o formato de gestão das informações de Telemetria começou a ser estruturado, focado no levantamento de necessidades para a formação do setor de Inteligência Telemétrica - desde recrutamento de profissionais a infraestrutura tecnológica. Entretanto, antes desta entrega, foi necessário planejar o fluxo de informações e responsabilidades com as áreas de Recursos Humanos e Operação. 
No primeiro momento, discutiu-se sobre o perfil profissional do responsável pelas análises dos dados de Telemetria. A situação requeria um profissional responsável por emitir e analisar os relatórios de Telemetria, monitorando a performance operacional tanto dos veículos quanto dos condutores, no qual este viria a contribuir para a otimização de resultados e o cumprimento dos objetivos estabelecidos pelo Grupo NSO.

Após discussão e orientação com a área de Recursos Humanos do Grupo NSO, definiu-se que este profissional teria como principais atividades:

Emitir e analisar relatórios de performance operacional, através do monitoramento de equipamentos e veículos em sistema de Telemetria;

Efetuar o cadastro dos motoristas no sistema de Telemetria, para identificação e liberação das chaves de ID;

Elaborar planejamento de reuniões mensais para devolutiva da performance aos envolvidos no processo de monitoramento;

Transmitir as áreas de Manutenção e Operação as análises dos relatórios de Telemetria, sinalizando eficiência operacional de condutores e veículos, destacando incidências de falhas;

Disponibilizar para a área de Recursos Humanos relatório com baixa performance de condutores, elencando os pontos para serem abordados em treinamentos específicos e campanhas de comunicação;

Subsidiar área Jurídica através de históricos operacionais com evidências de má conduta operacional;

Auxiliar no desenvolvimento de normas e procedimentos relativos a gestão por Telemetria, visando contribuir para a otimização de resultados e cumprimento dos objetivos estabelecidos;

Manter-se atualizado as práticas e tecnologias aplicáveis ao setor;

Executar outras atividades pertinentes, previstas em normas e procedimentos da área.

Concluiu-se então que estes atributos deveriam estar associados a função de Técnico de Telemetria, onde este deve se reportar ao Gerente de Manutenção. Como requisito mínimo na seleção deste profissional, considera-se:

Ensino Médio Completo. Desejável especialização ou treinamento específico em interpretação de dados de Telemetria;

Experiência de até um ano;

Conhecimentos Técnicos em plataforma Microsoft / Office, Estatísticas, Rotinas de Logística, Noções de Elétrica, Mecânica Veicular e Rastreamento Veicular;

Competências comportamentais, como Planejamento e Organização, Comunicação, Relacionamento Interpessoal, Solução de problemas, Determinação, Busca de melhoria e aprendizagem, Adaptação a mudanças, Foco em resultado;

Característica / Habilidades, como Senso crítico, Agir sob pressão, Atenção concentrada, Dinamismo, Objetividade e Sinergia.

Uma vez selecionados os colaboradores Técnicos de Telemetria, estes iniciaram o processo de integração com as áreas de Operação e Recursos Humanos a partir da disponibilização das chaves de ID ao motorista. Os operadores passam pelo treinamento de apresentação dos eventos monitorados por Telemetria (ex.: 
aceleração, frenagem, curva, velocidade, etc.) e recebem sua chave de ID, sob assinatura de termo de responsabilidade. Este formulário é base para cadastrar o motorista e sua respectiva chave no sistema informatizado dos dados de Telemetria. Neste momento, o motorista está apto a operar o veículo identificando-se a ele com sua chave ID. NOTA: Caso o motorista venha a perder sua chave ID, esta deverá ser reposta com consequente atualização cadastral, onde a chave deverá ter o desconto de seus custos ao responsável pela perda.

Ocorrendo a operação do veículo, o Grupo NSO optou por monitorar sete indicadores de performance operacional, ou chamados "eventos de condução", sendo quatro destes associados a segurança e três ligados a consumo de combustível conforme o detalhamento a seguir.

Segurança:

Aceleração Brusca (AB);

Frenagem Brusca (FB);

Curva Brusca (CB);

Excesso de Velocidade (EV).

Consumo de combustível:

Condução fora da faixa verde (FFV);

Excesso de rotação (ER);

Marcha lenta excessiva (MLE).

Ao processar estes sete indicadores, é gerada a performance operacional do veículo, do motorista, da linha operada, individualmente ou agrupado. O resultado destas análises poderá direcionar o motorista para treinamento inloco ou em sala de aula, ou até para tratamento disciplinar. Em determinado caso, o tratamento disciplinar pode levar ao desligamento do motorista, logo, este deve devolver a chave ID ao setor de Telemetria em seu processo rescisório, a fim de ser formatada pelo Técnico e cedida a um novo motorista.

Dando sequencia com os treinamentos, os resultados também podem embasar campanhas de Recursos Humanos e Comunicação, na intenção de expandir a cultura de boa condução veicular. Esta boa condução é medida pela performance dos motoristas, veículos e linhas em ranking específico.

A fim de obter a melhor métrica para avaliação da performance operacional, seja por motorista, por linha ou por veículo, desenvolveu-se um método inspirado no atual formato de medição da confiabilidade de frota (com o indicador MKBF). O método visa medir a influência do total de quilometragem percorrida correlacionado com o total de eventos de condução registrados. Este indicador, especialmente desenvolvido no Grupo NSO para interação exclusiva com os dados de Telemetria, denominou-se MKBE - Mean Kilometer Between Event (quilometragem média entre eventos - de condução - em português). Quanto maior a quilometragem média, melhor a performance daquilo que é analisado. O MKBE é representado na formula a seguir: 


$$
M K B E=\frac{\text { total de quilometragem da operação da frota }}{\text { total de eventos de condução }}
$$

Mostra-se na Figura 8 a estruturação deste gerenciamento, identificando a responsabilidade de cada área e setor no processo de gestão das informações de Telemetria:

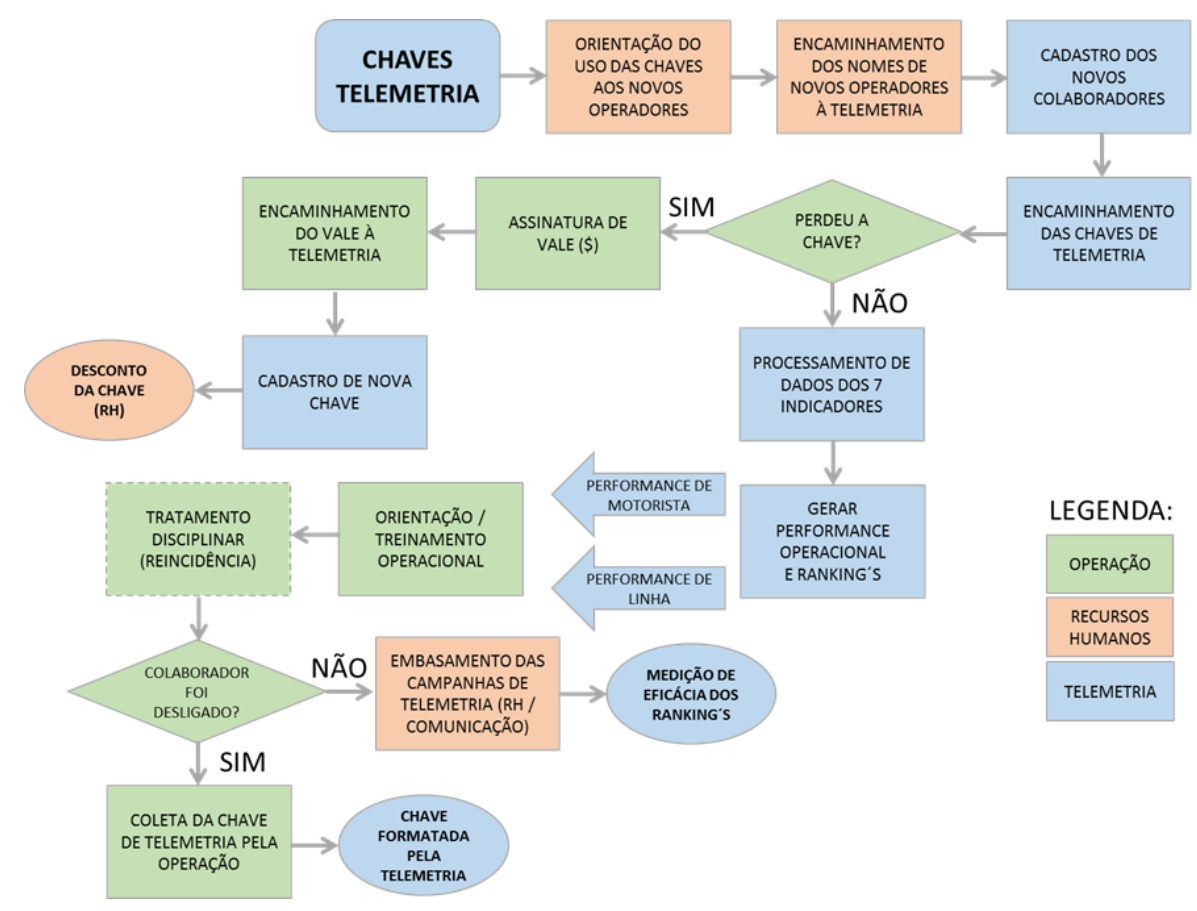

Figura 8. Estrutura de gerenciamento.

\subsection{Implementação}

Uma vez apresentados os resultados dos testes e formatada a estrutura gerencial com as áreas de Recursos Humanos e Operação, iniciou-se a fase de implementação, consistindo no planejamento inicial da aplicação das unidades de Telemetria pelas frotas das garagens do Grupo NSO, com a devida discussão de parâmetros dos eventos e estratégias para as instalações e treinamentos. Este ponto de partida motivou o desenvolvimento do setor de Inteligência Telemétrica do Grupo NSO, conciliando com os planos de divulgação da comunicação interna sobre recomendações para aumento da performance dos eventos de condução.

Um ponto importante da fase de implementação foi o desenvolvimento do modelo de condução padrão, o que motivou explorar um novo profissional na função de "Monitor Técnico-Operacional" (MTO). Este profissional ter por objetivo apresentar ao motorista os seus respectivos relatórios de performance e orientá-lo sobre o formato correto e adequado de dirigir. Essa tarefa é realizada no ambiente de trabalho do motorista, ou seja, enquanto ele está em Operação, o que possibilitou correções práticas e imediatas, sobretudo otimizando o tempo de treinamento em sala de aula. 
Contabilizam-se neste período de implementação:

Mais de 1.500 colaboradores treinados;

Mais de 120 horas de treinamento;

Mais de 200 turmas;

600 instalações realizadas;

Disponibilidade de equipe por 24 horas.

A seguir, apresenta-se uma relação histórica de todo o momento de implementação do Projeto Intelemétrica:

2015

Maio: Primeiro contato com o fornecedor das soluções de Telemática.

Setembro: Instalação dos equipamentos pilotos nas empresas NSO.

Outubro: Primeira reunião com Operação.

Dezembro: Trabalho de Campo com MTO e definição de Padrão de condução.

2016

Janeiro: Apresentação de resultados dos testes-piloto a Direção do Grupo NSO.

Fevereiro: Reunião de análise de Recursos Humanos para criação do setor de Inteligência Telemétrica.

Março: Negociação das unidades de Telemetria para os veículos; Reuniões para definição de parâmetros, estratégias de instalações e treinamentos.

Abril: Instalação na VSB Unid. Mangalot.

Maio: Desenvolvimento do setor de Inteligência Telemétrica; Início dos treinamentos na VSB Mangalot.

Junho: Instalação na VSB Unid. Jaguara; Desenvolvimento de material para comunicação e orientação interna; Início dos treinamentos na VSB Unid. Jaguara.

Julho: Instalação na VCC Unid. Caieiras; Início dos treinamentos na VCC Unid. Caieiras.

Agosto: Instalação na AVU Unid. Santana de Parnaíba; Início das atividades com o MTO.

Setembro: Desenvolvimento do painel de indicadores.

Outubro: Desenvolvimento de Heatmaps (mapa de calor, em português); Instalação (teste) de interface para feedback do motorista.

Novembro: Aplicação das instalações na VSB Unid. Jaguara.

Dezembro: Estreia do "Businho" - mascote da boa condução; Entrega do Projeto Intelemétrica.

\subsection{Setor de Inteligência Telemétrica}

Das principais entregas do Projeto Intelemétrica, destaca-se a criação de um setor dedicado ao processamento de dados, análise e gestão exclusiva do obtido através da Telemática. Trata-se setor de Inteligência Telemétrica (ilustrado na Figura 9), que se responsabiliza pelas análises telemáticas de ordem operacional e técnica. Sua estrutura comtempla espaço para disposição de equipamentos de informática e instalações dos Técnicos de Telemetria. Da mesma forma, oferece ambiente completo de monitoramento e ponto de encontro para reuniões de trabalho com os motoristas, monitores Técnico-Operacionais e gestores de Manutenção, Operação e Recursos Humanos do Grupo NSO. 


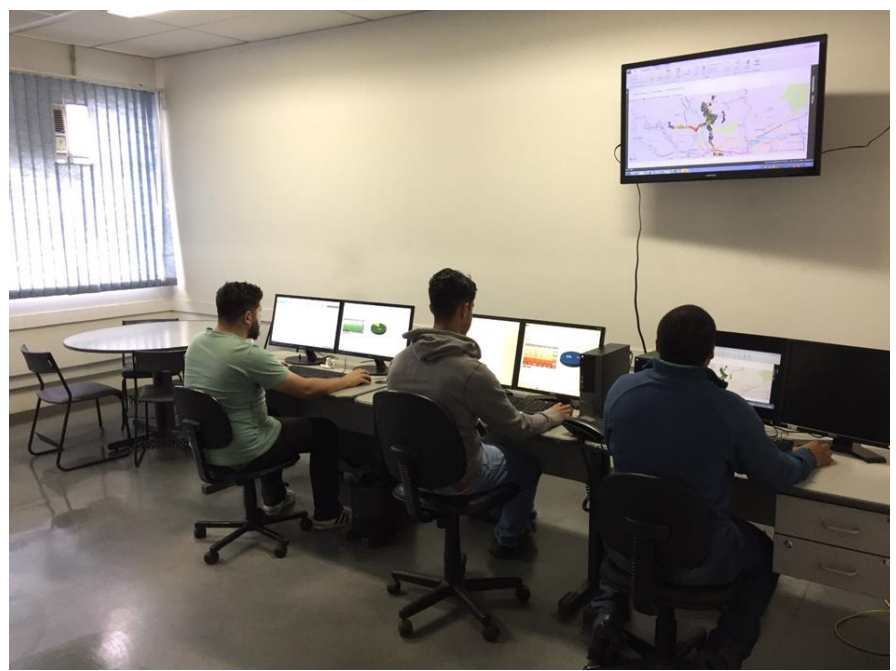

Figura 9. Setor de Inteligência Telemétrica.

Detalhadamente, produz:

Análise das variações semanais da performance operacional;

Monitoramento da performance do equipamento, sinalizando necessidade de aferição;

Apresentação em reuniões de fechamentos mensais com registro em Ata;

Orientação dos Monitores Técnico-Operacionais;

Processamento de Dados diários;

Cadastros de Motorista;

Criação e análise de mapas de calor (heatmap) da localização dos eventos;

Desenvolvimento de painéis dos indicadores de condução segura e ranking de performance dos motoristas;

Desenvolvimento de relatórios detalhados e específicos de acordo com a atividade operacional;

Medição do nível de utilização de chaves ID.

Na Figura 10 a seguir, exemplo de painel de navegação onde é possível detalhar os principais eventos de condução a partir da visualização do indicador MKBE total de cada empresa do Grupo NSO.

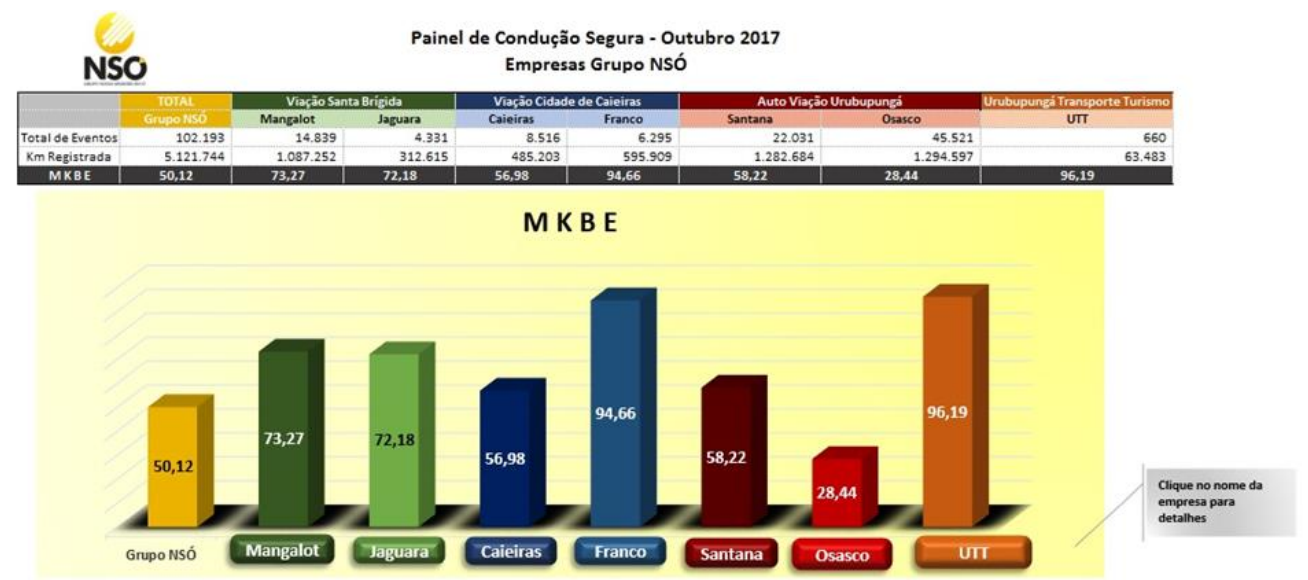

Figura 10. Painel de Condução Segura. 


\subsection{Monitores Técnico-Operacionais}

Transformando a interpretação dos indicadores do MKBE em ações, entra em cena o Monitor Técnico-Operacional (MTO), profissional responsável por acompanhar o desempenho dos motoristas inloco, observando e orientando a aplicação adequada dos conceitos e práticas de condução padrão adotadas pelo Grupo NSO. Através da análise dos relatórios dos indicadores de eventos de condução segura, apresenta-se ao motorista avaliado sua situação de performance, visando o progresso de seu desempenho após as orientações de campo. O objetivo principal deste profissional é possibilitar, além do aumento da performance individual do motorista, a satisfação do passageiro transportado, o aumento da segurança operacional e eliminação de infrações. A Figura 11 a seguir ilustra momento de orientação de motorista pelo MTO:

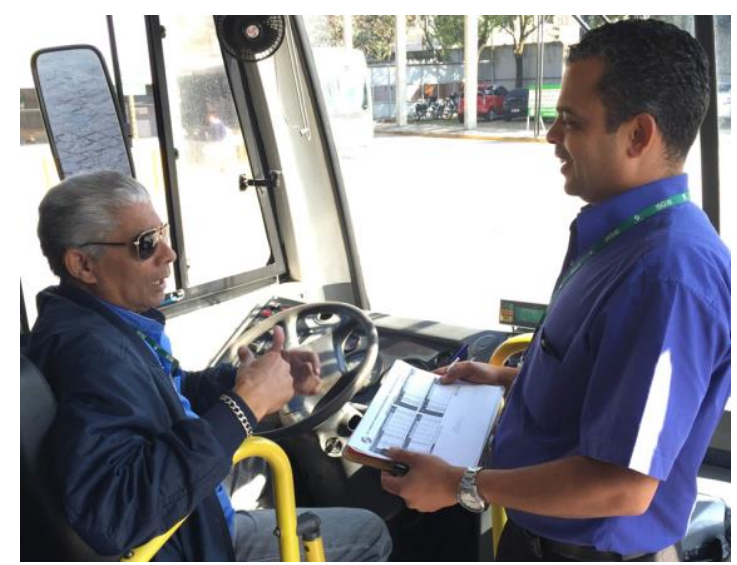

Figura 11. MTO em orientação técnica.

Em descrição detalhada das atividades do MTO:

Realizar acompanhamento operacional, observando na prática a correta aplicação dos conceitos técnicos e as diretrizes da empresa;

Acompanhar o desempenho dos Motoristas, constatando os conceitos apresentados durante Treinamento de direção defensiva e condução econômica, por exemplo;

Através de relatórios recebidos pelo setor de Inteligência Telemétrica, o Monitor Técnico saberá quais serão os Motoristas que estarão com baixa ou alta performance, planejando desta forma os acompanhamentos práticos que irão realizar;

Identificar em Relatório Operacional os aspectos positivos / negativos da conduta operacional do Motorista avaliado, acompanhando e registrando em formulário apropriado a orientação dada quando necessário;

Realizar atendimentos solicitados pelos Motoristas, como dificuldades de trajeto, acompanhando o Motorista solicitante e observando as dificuldades mencionadas, como: condições do Viário, desempenho do veículo, e outras dificuldades e/ou dúvidas de condutas mencionadas;

Realizar acompanhamentos esporádicos dos Motoristas em linhas, baseados em solicitações gerenciais específicas (Manutenção e/ou Operação), tomando como base os Índices de infrações cometidas, as reclamações informadas através do Serviço de Atendimento ao Cliente e/ou órgãos gestores de transporte, bem como o indicador de desempenho MKBE, gerando Relatório Gerencial de acompanhamento;

Checar o progresso dos Motoristas que estão sob avaliação junto ao MTO. 


\subsection{Comunicação Interna}

Complementando a tarefa de fixar as orientações do motorista, uma intensa atividade de comunicação interna foi desenvolvida, adotando a linguagem do cotidiano do operador, de modo a assimilar as orientações de forma mais simplificada e direta. Nas ilustrações a seguir, observam-se exemplos de divulgações em painéis orientativos e jornais internos - com a criação de personagem lúdico para a campanha de condução segura, chamado "Businho":

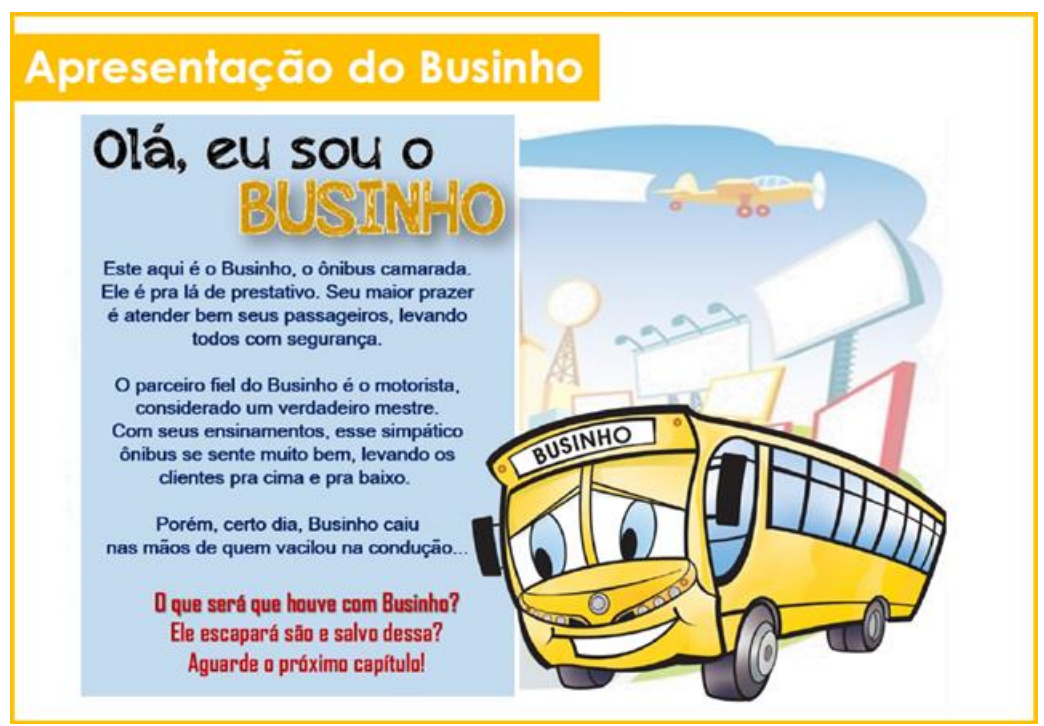

Figura 12. Mascote da condução segura.

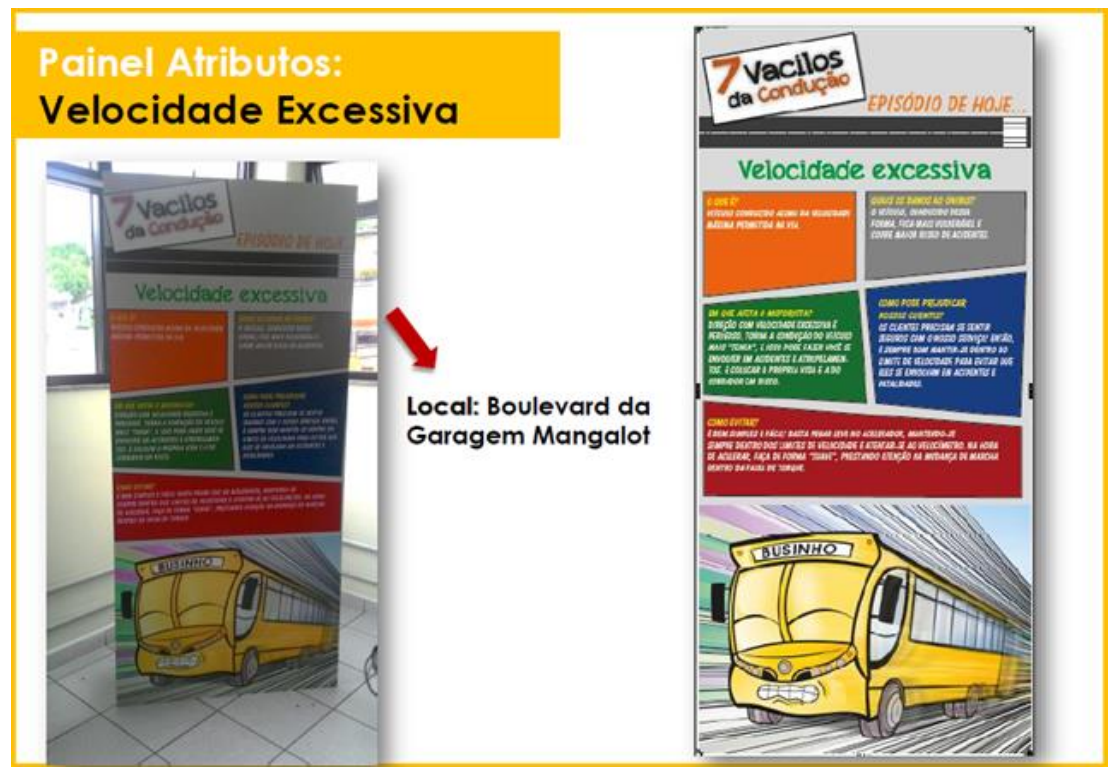

Figura 13. Painel de Atributos posicionado. 


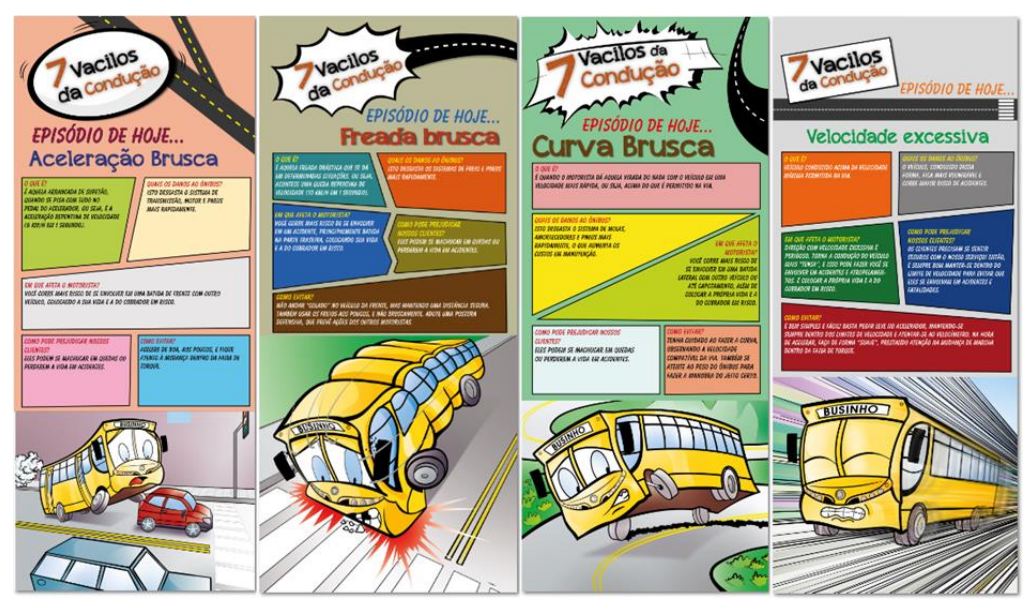

Figura 14. Painéis de Atributos da condução segura.

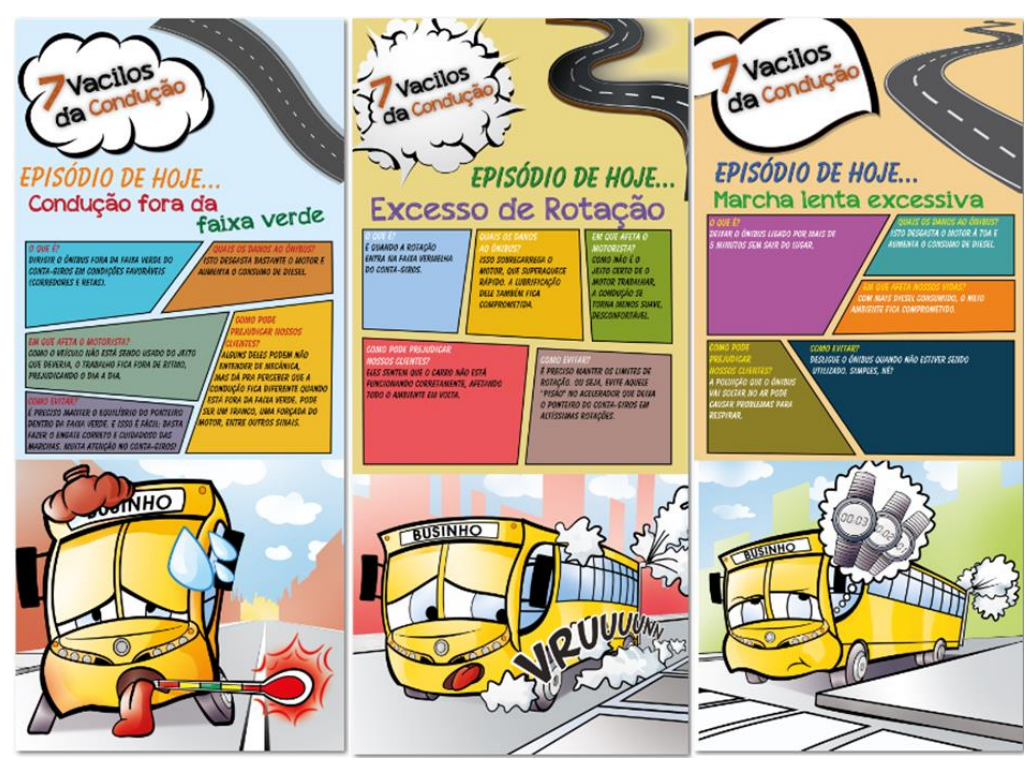

Figura 15. Painéis de Atributos da condução econômica.

\section{RESULTADOS}

Desde o início do projeto, observou-se constante evolução positiva do indicador de quilometragem média entre eventos de condução (MKBE). Isso foi dado principalmente ao aumento de desempenho do motorista pós-orientações dos Monitores Técnico-Operacionais, mas acima de tudo, fundamental adesão da cultura de boa condução pelos operadores. É comum observar no dia-a-dia dos motoristas a discussão comparativa entre seus indicadores individuais, tornando a gestão em uma 'competição sadia'. O passageiro também sente esta evolução, e um dos primeiros indicativos que despertou a medição de resultados foi a redução de reclamações por passageiro transportado pelo Grupo NSO, obtendo melhora de $6,2 \%$ entre os dois últimos semestres analisados.

Consequentemente, medem-se exemplos deste aumento de performance de condução segura através dos resultados da redução de quedas acidentais no interior do ônibus entre outros níveis de acidente, com ou sem vítima. Através desta leitura, pode-se concluir os reflexos da diminuição das indenizações, geração de boletins de ocorrência, processos judiciais, condenações, sobretudo os impactos na mídia, na imagem da empresa e na sociedade. Neste 
ensejo, observam-se os efeitos positivos no consumo de combustível e aumento da confiabilidade técnica da frota.

\subsection{Evolução dos Indicadores}

Na Figura 16 a seguir, observa-se a evolução exponencial do indicador MKBE total do Grupo NSO nos últimos 12 meses de operações com monitoramento via Telemetria:

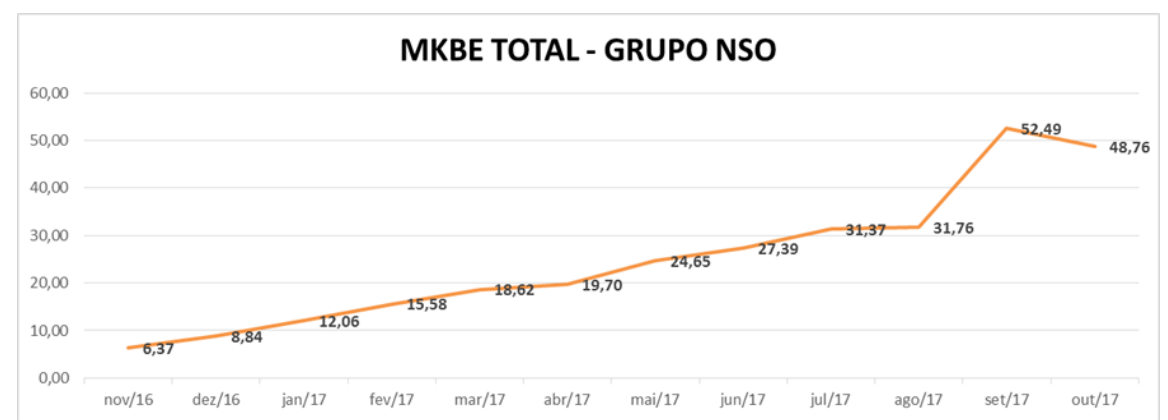

Figura 16. Evolução do MKBE total do Grupo NSO.

Detalhadamente, apresenta-se na Tabela 2 a evolução do MKBE por evento de condução segura:

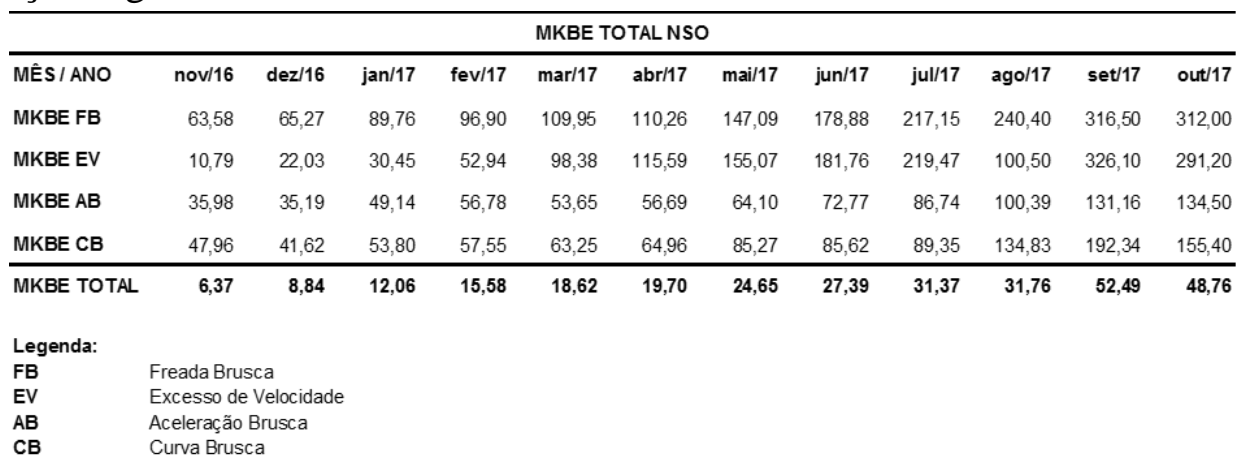

Tabela 2. Evolução do MKBE por evento de condução segura.

Em função do aumento de desempenho, efeitos de melhoria em outros indicadores como quedas acidentais de passageiros no interior do ônibus - principalmente associado a diminuição das incidências de $\mathrm{FB}, \mathrm{AB}$ e $\mathrm{CB}$ - possibilitaram redução de $17 \%$ entre semestres (nov/16 a out/17) nas incidências, como demonstra o gráfico a seguir na Figura 17:

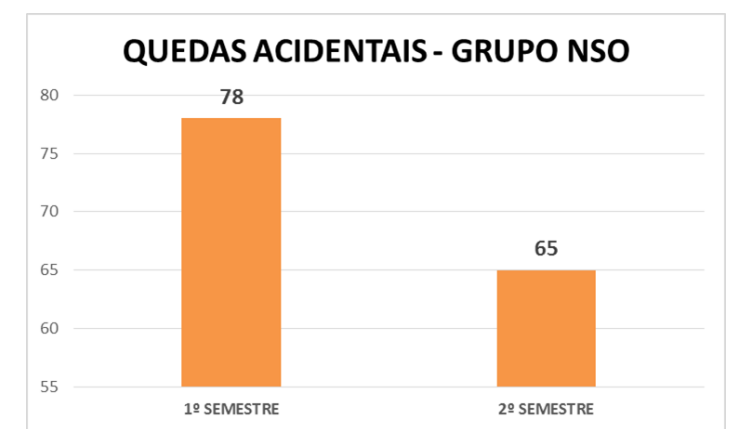

Figura 17. Redução das Quedas Acidentais no Grupo NSO. 
A partir de um modo de condução mais regular, é notável o formato menos abusivo no qual o veículo é submetido, com o uso equilibrado do sistema de freio, efeitos de arrancada cada vez mais controlados e aceleração, velocidade e marcha lenta em limites que favorecem menores emissões de gases poluentes e a redução de consumo de combustível em 3,7\%, da forma apresentada na Figura 18:

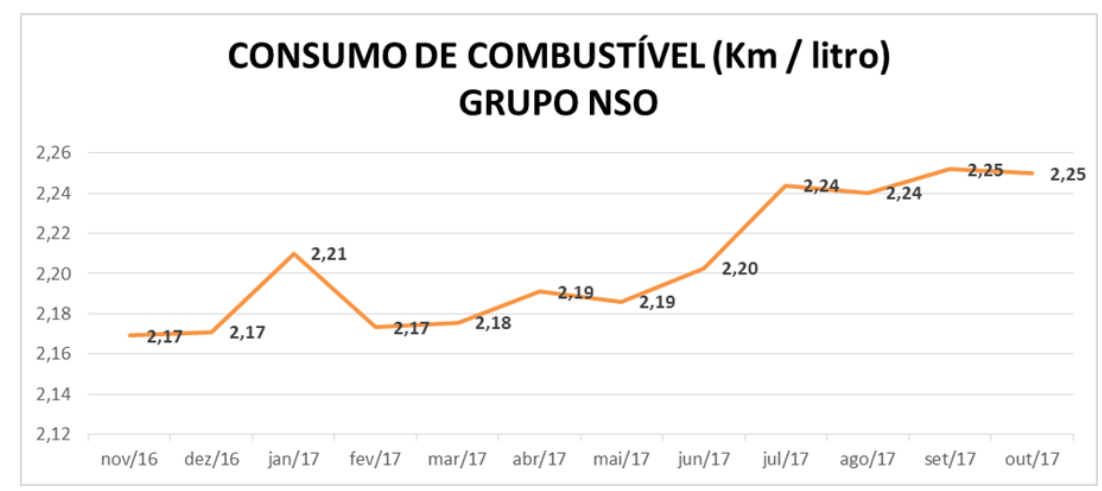

Figura 18. Consumo de combustível no Grupo NSO.

Com a frota condicionada a uma situação de severidade operacional menor, com uma condução veicular mais controlada, observam-se na Figura 19 a seguir a evolução da quilometragem média entre falhas (MKBF) na frota do Grupo NSO:

\section{CONCLUSÃO}

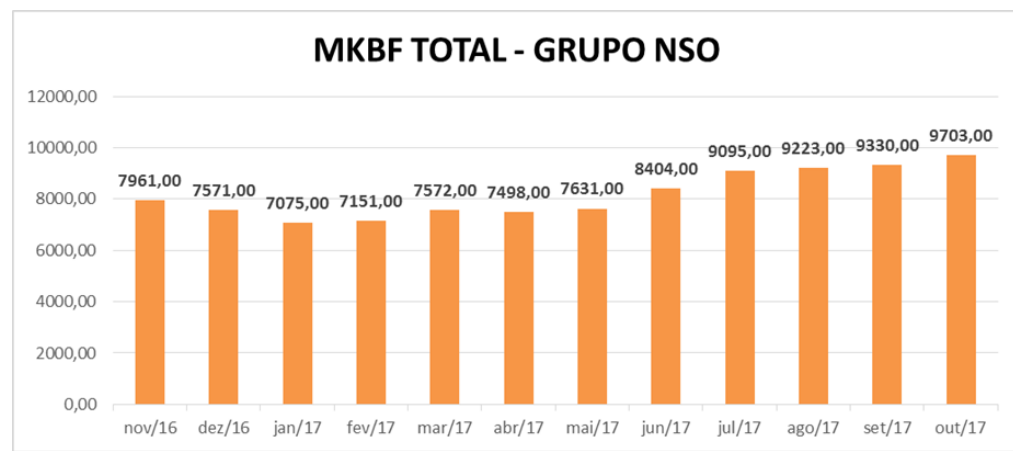

Figura 19. Evolução do MKBF no Grupo NSO.

O estudo e as pesquisas foram determinantes para a formatação do Projeto Intelemétrica, concluindo-se bom desempenho pós-implementação, principalmente associado aos resultados obtidos e estabelecimento de nova cultura de alta performance. Observa-se que para manutenção e evolução destes resultados, é fundamental a gestão intensiva de todas as áreas corporativas diretamente ligadas ao projeto.

Conclui-se fundamental a análise detalhada dos fornecedores desta tecnologia - em abundância no atual mercado - visando selecionar o melhor produto e parceiro que apoie a elevação dos resultados.

A liberação integral da rede CAN pelas montadoras pode ser fator de decisão em processo licitatório do transporte público. Portanto, é tema que merece atenção e estudo dos fabricantes, tal como já praticado em cidades de outros países. 
O setor de Inteligência Telemétrica trouxe um meio de interação entre as áreas de Operação, Manutenção e Recursos Humanos em processo simplificado que compartilha da experiência destas áreas, tornando as etapas de planos de ações mais assertivas.

Criar a métrica com o indicador MKBE trouxe meio eficaz de nortear as boas práticas de condução segura e econômica, direcionando tomadas de decisões mais precisas aos gestores.

Logo, o Grupo NSO considera imprescindível o uso da Gestão Telemática para assegurar a regularidade e padrão de condução segura e econômica de suas frotas. É pratica do Grupo NSO o uso dos conceitos definidos no projeto para aprimorar as habilidades operacionais, sendo evitadas as ações punitivas. Pela análise dos resultados, conclui-se o aumento de segurança viária das frotas, da satisfação do passageiro transportado, da confiabilidade técnica e, efetivamente, da produtividade - qualificando o profissional diretamente envolvido neste resultado: o motorista. Em resumo: O Projeto Intelemétrica e suas entregas agregaram valor a organização.

\section{REFERÊNCIAS}

[1] SCHWAB, K. A Quarta Revolução Industrial. 1ª ed. São Paulo: Edipro, 2016. 11-12 p.

[2] BOSCH, R. Manual de Tecnologia Automotiva. 25a . ed. São Paulo: Edgard Blücher, 2005. 1114-1168 p.

[3] GÁSPÁR, P. et al. Highly Automated Vehicle Systems: Architecture of Fleet Management Systems. Disponível em: <http://www.tankonyvtar.hu/hu/tartalom/tamop412A/2011-

0042_jarmurendszerek_iranyitasa_angol/ch14s04.html>. Acesso em: 01 set. 2017.

[4] FERREIRA, M. L. Automação de metodologia para avaliação da demanda de passageiros para transportes públicos na mobilidade urbana por meio da tecnologia RFID. 2015. 69 p. Dissertação (Mestrado em Ciências)- Escola Politécnica, Universidade de São Paulo, São Paulo, 2015.

[5] BAZANI, Adamo. Licitação dos ônibus de São Paulo deve usar planilha que considera custos maiores dos empresários. Disponível em: $<$ https://diariodotransporte.com.br/2017/08/22/licitacao-dos-onibus-de-sao-paulo-deve-usarplanilha-que-considera-custos-maiores-dos-empresarios/>. Acesso em: 04 set. 2017.

[6] GUIMARÃES, A. A. Eletrônica Embarcada Automotiva. 1a. ed. São Paulo: Érica, 2007. $216 \mathrm{p}$.

[7] RASPANDI, M. P. Transporte inteligente. Anuário de Gestão \& Eficiência de Frotas, São Paulo, n. 12, p. 30-32, 2015. 